\title{
Collaborative Social Media Campaigns and Special Collections: A Case Study on \#ColorOurCollections
}

\section{Introduction}

From February 1 to February 5, 2016, The New York Academy of Medicine Library launched \#ColorOurCollections, a social media campaign that invited libraries, museums, and other cultural institutions to share images from their collections for users to color and repost on Twitter, Facebook, Instagram, and Pinterest. The current popularity of adult coloring books inspired the idea. Large print runs and parallel sales of adult coloring books by Joanna Basford, Dover's Creative Haven line, and others demonstrate a surge of interest in adult coloring, a format that encourages participatory art-making. ${ }^{1}$ In 2015 , coloring books dominated the trade paperback bestseller list, accounting for " $13.5 \%$ of the total [list] positions." Recently, librarians have responded to the trend, forming library coloring clubs and adult coloring therapy programs. ${ }^{3}$ In this article, we discuss the goals of \#ColorOurCollections, its successes and challenges, and offer recommendations for special collections in libraries interested in embarking on social media campaigns.

\section{Social Media Use in Libraries}

A number of articles and monographs have recently addressed library use of social media, in many cases focusing on libraries with special collections. A 2013 survey conducted by Heyliger, McLoone, and Thomas suggests that most special collections use social media platforms with the primary goal of increasing the visibility of their collections as resources. ${ }^{4}$ Dickson and Holley (2010) have shown that social media platforms like Twitter and Facebook offer a mechanism for delivery of content to a large audience of users already comfortable with the interfaces of the platform. ${ }^{5}$

1. Judith Rosen, “Coloring Books Grow Up,” Publishers Weekly 262, no. 20 (May 18, 2015): 5-7; Francine Fialkoff, "Dover, Others, Cash in on Adult Coloring," Library Journal 140, no. 13 (August 1, 2015): 20.

2. Daisy Maryles, “The Year in Bestsellers," Publishers Weekly 263, no. 2 (January 11, 2016): 20-25.

3. Fialkoff, "Dover, Others, Cash in on Adult Coloring."

4. Sean Heyliger, Juli McLoone, and Nikki Lynn Thomas, "Making Connections: A Survey of Special Collections' Social Media Outreach," American Archivist 76, no. 2 (Fall/Winter 2013): 374-414.

5. Andrea Dickson and Robert P. Holley, "Social Networking in Academic Libraries: The Possibilities and the Concerns," New Library World 111, no. 11/12 (2010): 468-79, doi:http:// dx.doi. org/10.1108/03074801011094840.

*(C) 2016 by Anne Garner, Johanna Goldberg, and Rebecca Pou (CC BY-NC [https:// creativecommons.org/licenses/by-nc/4.0/]). 
Library literature has also emphasized the resources that institutions need to make their outreach efforts salient. The 2014 monograph Marketing and Social Media: A Guide for Libraries, Archives, and Museums by Christie Koontz and Lorri M. Mon offers guidelines for aligning institutional goals with more practical social media strategies. ${ }^{6}$ Other scholars have focused on the importance of the technological and human resources needed to implement these strategies. Overwhelmingly, the literature stresses the importance of dedicated staff committed to strategic thinking and execution to ensure the success of social media initiatives. ${ }^{7}$ Shulman, Yep, and Tomé (2015) have also suggested the usefulness of NodeXL and other software to track and analyze social media networks and statistics. ${ }^{8}$ This paper discusses the use of Twitter Analytics, Facebook Insights, Hashtracking, and Wordpress Analytics in analyzing our campaign.

Still other publications have addressed the potential for lasting outcomes of special collections' online outreach. Amanda Kraft and Aleck F. Williams, Jr. (2016) demonstrate that hashtag campaigns in academic libraries offer new opportunities for students to engage with library collections and that the element of interactivity is critical. ${ }^{9}$ Ann Dutton Ewbank's work (2015) suggests the vital role that influence plays in constructing a successful Twitter campaign. Ewbank argues for the value of institutional accounts vs. individual accounts and the importance of connecting with other institutional accounts for maximum reach. ${ }^{10}$ Building on these contributions, which largely discuss social media outreach in academic libraries, our article tracks the outcomes of a social media campaign by an independent research library.

\section{The New York Academy of Medicine Library}

Since its founding in 1847, The New York Academy of Medicine has been home to one of the most significant libraries in medicine and public health, safeguarding the heritage of medicine to inform the future of health. Today, we are largely a historical library, offering many of the formative texts of medicine and allied fields from the $16^{\text {th }}$ century forward. More broadly, our collections offer vital perspectives on the history of science, printing and the book, and our relationship to our bodies in sickness and in health over time. We are an independent library not connected to a museum

6. Christie Koontz and Lorri M. Mon, Marketing and Social Media: A Guide for Libraries, Archives, and Museums, (Lanham, Md.: Rowman \& Littlefield Publishers, 2014).

7. Dickson and Holley, "Social Networking in Academic Libraries"; Heyliger, McLoone, and Thomas, "Making Connections: A Survey of Special Collections' Social Media Outreach"; Jason Shulman, Jewelry Yep, and Daniel Tomé, "Leveraging the Power of a Twitter Network for Library Promotion," Journal of Academic Librarianship 41, no. 2 (March 2015): 178-85.

8. Shulman, Yep, and Tomé, "Leveraging the Power of a Twitter Network for Library Promotion."

9. Amanda Kraft and Aleck F. Williams Jr., "\#Shelfies Are Encouraged," College \& Research Libraries News 77, no. 1 (January 2016): 10-13.

10. Ann Dutton Ewbank, "Library Advocacy through Twitter: A Social Media Analysis of \#savelibraries and \#getESEAright," School Libraries Worldwide 21, no. 2 (July 2015): 26-38. 
or university. Our independence gives us the freedom to be creative, but it doesn't provide the support or built-in audience that most collections of our depth have.

The Academy's social media efforts are currently concentrated on four platforms: Instagram, Twitter, Facebook, and Wordpress. The Library's Wordpress blog, "Books, Health and History," active since 2012, produces one to two stories about the collections every week and includes posts pitched toward the history of medicine community as well as to a wider public. On Twitter, active since 2010, we share a mixture of original and retweeted content, including images from the collection and curated content related to our programming and the history of medicine, science, and public health in New York City and beyond; news about preservation and conservation; and the history of the book. Our Facebook and Instagram feeds also typically promote Library happenings, as well as collection material (frequently with some overlap and expansion of our Twitter content). ${ }^{11}$

Koontz and Mon advocate that "social media should be used to advance the mission, goals and objectives of the organization." 12 The Academy Library's mission is threefold: 1) to preserve and promote the heritage of medicine and public health; 2) to explore the connections between history and the humanities and contemporary medical, health policy, and public health concerns; and 3) to make the history of medicine and public health accessible to public and scholarly audiences. We have endeavored to promote the Library's overall mission, while collaborating with a larger community of libraries worldwide invested in preserving the history of the book and the history of science and medicine. Our internal social media strategy defines our primary objectives in two ways: 1) to promote the Library's collections; and 2) to create links and build bridges to similar organizations. These goals have led us to share our content in line with the Library's larger mission, giving context to collection items for an online audience-both scholars and enthusiasts-we would not be able to reach otherwise. \#ColorOurCollections addressed these social media goals in a more ambitious way than our day-to-day content.

\section{\#ColorOurCollections}

We knew from the beginning that the success of \#ColorOurCollections would depend on the participation of other libraries and museums. By extending an invitation to our peers, we aimed to establish long-term relationships with potential for further online collaboration and partnership. Partnering with other institutions would also raise their awareness of the kinds of collections we have and encourage use of the rich materials our Library holds.

11. As of this writing, our Twitter account has 3,400 followers, with 2,989 likes on Facebook and 1,002 on Instagram (we joined Instagram in March 2015).

12. Koontz and Mon, Marketing and Social Media. 


\section{Methodology}

\#ColorOurCollections developed organically. An informal Twitter exchange with the Biodiversity Heritage Library in early December 2015 led to the idea, although we had some experience with "coloring our collections," having produced printed coloring books for children in the past few years.

\section{NYAMHistory}

(d) NYAMHistory

\section{@BioDivLibrary@SiobhanLeachman Love! We made a coloring book: bit.ly/1PBaxgU Can we start a "coloring our collections" day!?}

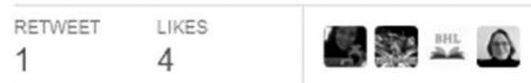

ह2) Reply to @BioDivLibrary @SiobhanLeachman

Siobhan@SiobhanLeachman.3 Dec 2015

(3) .NYAMHistory @BioDivLibrary Sounds great! I think I need to treat myself to some fancy pens :-)
4
47
$\approx$
2

BHL@BioDivLibrary·3 Dec 2015

@NYAMHistory @SiobhanLeachman So cool! Recognize those images from our collection too! We totally need a \#ColorOurCollections day!

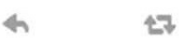

$\approx$

○ 3

\section{Illustration 1}

The initial tweet that catalyzed the \#ColorOurCollections campaign.

Early on, our three-person social media team consulted with management and our institution's communications department and gained their approval to proceed with the campaign. Support from the communications department was crucial, as they provided the graphic design skills needed to make our coloring book. It is worth noting that we did not anticipate how large the campaign would grow. Our expectations for the amount of work and time involved, especially for the social media team, were far less significant than what was actually required. Nevertheless, even as the campaign became increasingly demanding, we had the support of management, who clearly saw the benefits to our institution. 
Once our social media team committed to launching the campaign in mid-December, we identified three main tasks: recruit participants, create our coloring book, and spread the word. Our first step was to e-mail institutions directly. A month before the campaign, we e-mailed a proposal to about 130 institutions. We selected these institutions because we were already connected on social media and thought their collections would have great source material for coloring books. We also sent announcements to several listservs (Exlibris, Archives \& Archivists, and Archivists $\&$ Librarians in the History of Health Sciences) and posted an announcement on our blog. ${ }^{13}$ From these efforts, approximately 35 institutions expressed interest prior to the beginning of February.

To make participation as easy as possible, the only requirements were to post images suitable for coloring on any social media platform from February 1 through February 5 using the hashtag \#ColorOurCollections. We felt that having numerous guidelines might exclude institutions with small staffs or limited resources. \#ColorOurCollections content could be as simple as a scanned illustration posted to Facebook or as elaborate as a $20+$ page booklet made available for download.

For our own content, we elected to create a 20-page PDF coloring book, working with the graphic designer in our institution's communications department. Each page included the campaign hashtag, our social media handle (@nyamhistory) and blog URL (nyamcenterforhistory.org), and bibliographic information for the image source. We recycled content from our earlier coloring books and added five new images.

While current coloring trends favor intricate patterns, these are not easy to find in our collection's early printed books. Instead we identified illustrations with distinct lines, minimal shading, and empty spaces as ideal for coloring. We suspected animals would be popular, so natural histories featured prominently. For these, we chose images from Aldrovandi, Serpentum, et draconum historiae libri duo, 1640; Aldrovandi, De quadrupedib.' digitatis viviparis ..., 1637; Gesner, Historiae Animalium, Liber I, 1551; and Gesner, Thierbuch, 1563. We selected Scappi’s Opera, 1596, because its detailed kitchen scenes would be fun to color. Other sources included an anatomical atlas (Bidloo, Anatomia humani corporis..., 1685), an herbal (Blackwell, A Curious Herbal, 1739), and a book on drugs (Pomet, Histoire general des drogues, 1694). Of all our coloring sheets, Pomet's unicorns seemed to be colored the most, based on the colored sheets shared by our audience, showing that animals, even mythical ones, are a hit.

13. “\#ColorOurCollections February 1-5," Books, Health and History, January 6, 2016, available online at https:/ / nyamcenterforhistory.org/2016/01/06/colorourcollections-february-1-5/ [accessed 9 June 2016]. 

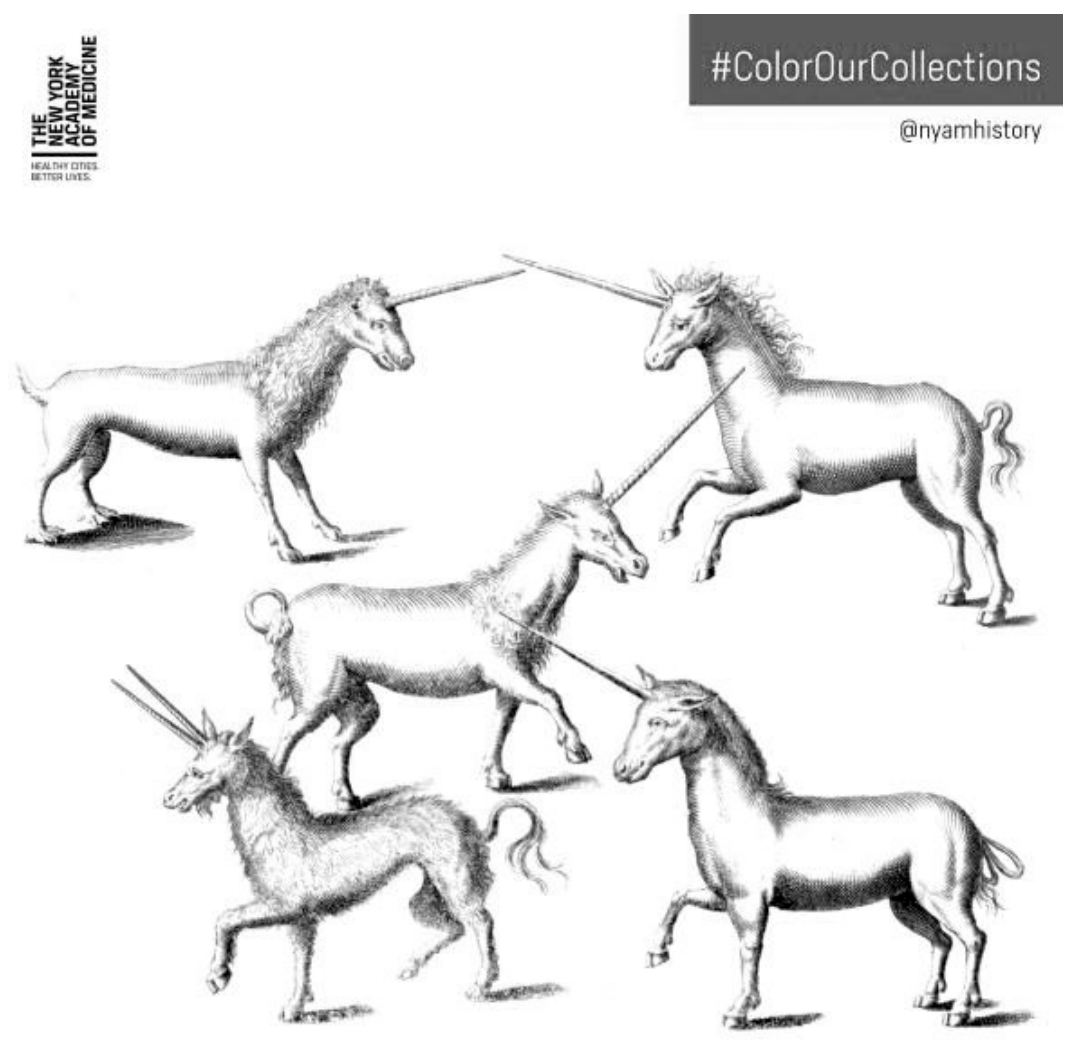

Pierre Pomet, 1658-1699. Histoire general des drogues... Paris: Jean-Baptiste Loyson [etc.]. 1694.

If you like this image, please visit or contact The New York Academy of Medicine Library at 212.822.7315 or library@nyam.org. Our collections are open to the public by appointment.

You may find more information about the Academy's Library on our blog "Books. Health, and History." at nyamcenterforhistory.org.

\section{Illustration 2}

Coloring sheet featuring unicorns from Pierre Pomet's 1694 Histoire general des drogues.

Once other institutions joined \#ColorOurCollections, the campaign took on a life of its own. Participants began promoting the event through their own channels. Institutions with no prior contact to us became involved. As originators of the campaign, we felt a responsibility to capture and aggregate \#ColorOurCollections content. To keep track of participants, we used an Excel spreadsheet, listing the institution, contact information, dates of contact, and notes on any questions or concerns. Since we were in direct contact with the early participants, this was easy to maintain during our initial outreach efforts; but, as institutions joined through 
word of mouth, we had to search for them. We also created a public Twitter list, adding new participants as they signed up. ${ }^{14}$ As institutions released their \#ColorOurCollections content, we kept a separate list of links to coloring sheets and books, blog posts, media mentions, and specific tweets of interest.

Both before and during the campaign, we posted actively about it on Twitter, Facebook, and Instagram, putting most of our efforts into Twitter, as Twitter is a fastmoving medium that had the highest volume of campaign participants. During the campaign week, our social media activity was almost entirely focused on the event. We shared our coloring sheets and blog posts several times a day on Twitter and attempted to retweet all participating institutions at least once during the week. We also shared sheets colored and posted by campaign enthusiasts. Unsurprisingly, Instagram had robust activity from colorists; most of our content there consisted of reposts of their work. Facebook posts included our blogs and media coverage of \#ColorOurCollections. To highlight the campaign across platforms, we designed a \#ColorOurCollections banner featuring our coloring page images (using the free online graphic design site Canva) to be used atop our Twitter and Facebook profiles and in each \#ColorOurCollections blog.

During the official \#ColorOurCollections week, we blogged about the campaign every day. Each post featured two of our coloring sheets, as well as a link to our full coloring book, and included background information on the image sources and links to their catalog records. The posts also highlighted other institutions' content and recognized the work of colorists. On the last day of the campaign, we posted a final blog entry providing our collected list of links to coloring sheets and books. ${ }^{15}$

Keeping up with the campaign was a tremendous amount of work; we automated what we could. We used IFTTT (ifttt.com), a tool that connects online platforms with "if this, then that" statements, or "recipes." Using IFTTT, tweets and Instagram posts using \#ColorOurCollections and \#ColourOurCollections were automatically sent to a Slack channel. Slack is a collaborative messaging app designed for the workplace, which our social media team uses for much of its communication. Two of our team members found this a useful way to track the hashtag's activity during the campaign, while the third found it overwhelming, preferring to use a hashtag search through the social media channels themselves. We had to alter our IFTTT recipe to prevent the Slack channel from being overrun with retweets.

14. "List Members," available online at https://twitter.com/NYAMHistory/lists/ colorourcollections/members [accessed 9 June 2016].

15. Rebecca Pou, Johanna Goldberg, and Anne Garner, “\#ColorOurCollections Roundup,” Books, Health and History, February 5, 2016, available online at https://nyamcenterforhistory.org/2016/02/05/ colorourcollections-roundup/ [accessed 9 June 2016]. 
IFTTT was also helpful with our Pinterest boards, which were created especially for \#ColorOurCollections. We used Pinterest to compile other institutions' coloring content and gather social media users' colored-in images, creating two boards: "\#ColorOurCollections" and "Our Collections, Colored." Through IFTTT, all Instagram posts with the hashtag were sent to Pinterest; staff had to move images from the "\#ColorOurCollections" board to the "Our Collections, Colored" board as appropriate. Images posted to Twitter were added to Pinterest manually by our staff, who attempted to include at least one image from every participating organization, along with colored-in images not also posted to Instagram and thereby already directed to Pinterest through our IFTTT Instagram recipe.

As mentioned earlier, the campaign was a considerable undertaking, especially during the \#ColorOurCollections week. All three of our social media team members devoted much of that week to the campaign. It was a group effort to keep track of participants and their content, update our lists, post our own content, react to social media questions and posts, write blog posts, and simply monitor the campaign.

\section{Results}

By the close of the \#ColorOurCollections week, 211 institutions had taken part, using 239 social media accounts. Of these, 232 posted to Twitter, while the remainder used other social media platforms only. These organizations represented libraries, special collections, digital collections, museums, historic homes, archives, and historical societies in 32 states within the United States and in Canada, the United Kingdom, France, Spain, Sweden, Australia, and New Zealand, covering a huge range of disciplines. They shared 103 coloring books and pages and 24 Facebook, Flickr, and Pinterest albums, along with an enormous number of one-off Twitter, Instagram, and Facebook posts of images to color. Coloring selections came from incunables, natural histories, botanicals, children's classics, anatomical atlases, yearbooks, patents, stained glass windows, historical photographs, and more. We knew the campaign had really made it, though, when it inspired this fake statistic:

Fake Library Stats

(@) FakeLibStats

Following

\section{At this moment, $14 \%$ of librarians are in a coloring-induced trance}

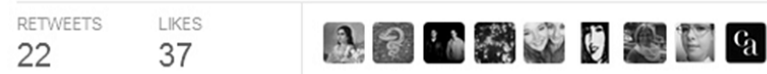

4:04 PM - 2 Feb 2016

\section{Illustration 3}

A sign that the campaign had caught on. 


\section{Overall Campaign Statistics}

Between January 31, 2016, and March 3, 2016-the period we tracked using the online tool Hashtracking — 5,230 contributors posted 9,573 tweets (2,342 original tweets, 7,021 retweets, and 210 message tweets) using \#ColorOurCollections, reaching 20,565,233 people. Although the majority of these tweets (almost 83\%) were posted from February 1 through February 5, we opted to track a longer period to get a sense of how the hashtag continued to be used post-campaign.

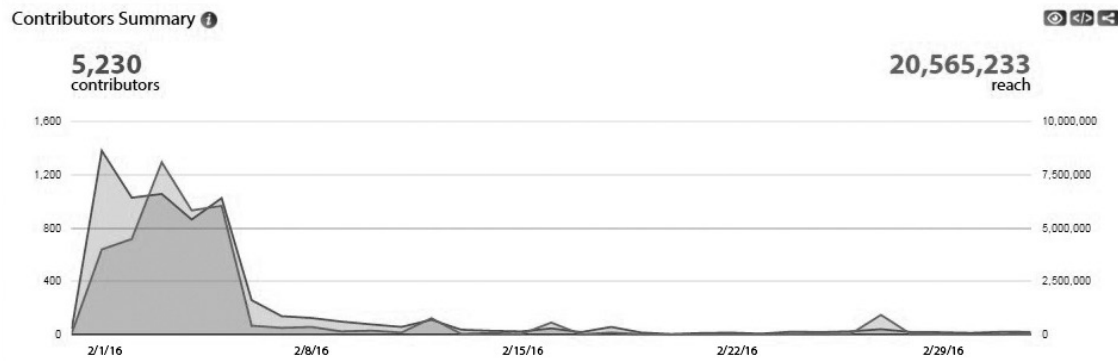

\section{Illustration 4}

Hashtracking stats from January 31, 2016 through March 3, 2016.

We had never coordinated a social media campaign of this size before-neither had our institution's communications department. Going into the campaign, we were unaware that most online management tools for hashtag tracking are designed to collect data during a campaign, not retrospectively. Many of these tools, like Keyhole, Tweetbinder, and Hashtracking, offer free trials. Some-like Tweetchup-are free but do not offer robust reporting or more than 10 days of data. We signed up for a Hashtracking account after the campaign ended. At that point, we could only go back in time to access data starting January 31. Even with a free trial, we paid a fee to access this historical data and were limited to tracking \#ColorOurCollections only, rather than both the American and British spellings of the hashtag. But because the majority of users tweeted with the American spelling or with both spellings, these statistics offer an excellent overall view of the campaign. Even so, given these limitations, they underestimate the amount of activity the campaign enjoyed.

Hashtracking tracked only the use of \#ColorOurCollections in Twitter. Instagram lists the number of times a hashtag was used, so we know that images have been posted with \#ColorOurCollections more than 500 times before, during, and after the week. We were not able to measurably track the hashtag's use on Facebook in real time, but we know the campaign was less active there based on searches in the platform. Still, some institutions, like the John J. Wilcox, Jr. Archives at William Way LGBT Community Center and the Alaska State Library and Historical Collections, participated only on Facebook. 


\section{Who Colored Our Collections?}

Many of the posts using the hashtag came from individuals sharing their coloredin pictures. While the majority of artists were adults, as anticipated, some were pictures colored by children and shared by their parents or teachers. Some images were colored and shared by institutional staff, but the majority came from people without apparent ties to the collections they colored, who found out about the campaign through content on their social media feeds. What we know about the experiences of the artists remains anecdotal, based on those who shared their thoughts on their social media accounts. One French Instagram user, @ suivez_le_fil, expressed delight at encountering a coloring sheet from Fuchs' De historia stirpium (1542) because she had written her masters' thesis on the book. In another case, user @eeevarose took a textile arts approach, translating a botanical woodcut depicting a poppy into an embroidery project. For future campaigns, we will invite participants to take a post-campaign survey so we can get more feedback about their experiences. We have a sense of scale from our Pinterest album: we pinned more than 450 colored images to our "Our Collections, Colored" board on Pinterest (either automatically from Instagram via IFTTT, or by hand through Twitter), indicating a high level of participation from colorers.

\#ColorOurCollections also brought collection images to an offline audience. The New York Botanical Garden's LuEsther T. Mertz Library hosted two lunchtime coloring sessions, both open to the public. University libraries printed copies of coloring pages for patrons to color, and many did so again after the campaign as a finals week destressor and shared their efforts on social media. Public librar-

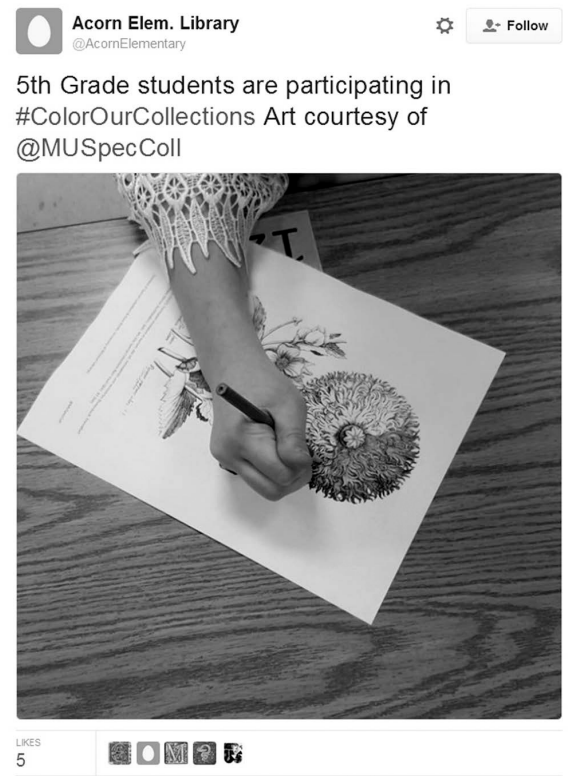
ies printed images shared during the campaign and used them in their programming. A number of elementary school libraries did the same, which is how a child attending Acorn Elementary School in Arkansas, for example, could color a $17^{\text {th }}$-century flower from the Special Collections of the University of Missouri.

\section{Illustration 5} Johann Theodor de Bry's 1641 flower bloomed in the care of students at Acorn Elementary Library in Arkansas.

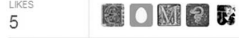




\section{Online Coverage}

The campaign received more than 30 mentions on blogs and online outlets, not counting participating organizations' blogs. This included coverage in popular web sources like Book Riot, Bustle, Open Culture (shared 25.1k times), Popular Science, and Mental Floss. ${ }^{16}$ Newspapers in Palo Alto, Reading (U.K.), and Waco covered the campaign with a local twist, while The Artstor Blog, School Library Journal, and Library Journal InfoDocket took an industry approach. ${ }^{17}$ Smaller, personal blogs also spotlighted the campaign. ${ }^{18}$ On January 27, someone used Ask MetaFilter to inquire about how to get started with adult coloring; two days later, someone replied linking the person to the campaign. ${ }^{19}$ Our communications department pitched the campaign to select media outlets, including The New York Times Arts Beat blog, Huffington Post, and The Daily Beast, but the majority of these mentions came organically as \#ColorOurCollections gained traction throughout the week.

16. Derek Attig, "Coloring Books from Libraries \& Museums," 2016, available online at http:// bookriot.com/2016/02/02/ coloring-books-libraries-museums-colorourcollections-week/ [accessed 9 June 2016]; JR Thorpe, "You Can Now Make Your Own DIY Adult Coloring Book From History's Most Amazing Book Illustrations," 2016, available online at www.bustle.com/articles/139459-you-cannow-make-your-own-diy-adult-coloring-book-from-historys-most-amazing-book-illustrations [accessed 9 June 2016]; "Free Coloring Books from World-Class Libraries \& Museums: The New York Public Library, Bodleian, Smithsonian \& More,” 2016, available online at www.openculture.com/2016/02/ download-free-coloring-books-from-world-class-libraries-museums.html [accessed 9 June 2016]; Kelsey D. Atherton, "The National Archives Released a Free Coloring Book of Weird Patents," 2016, available online at www.popsci.com/ color-in-these-patents-from-national-archives? src $=$ SOC \&dom $=\mathrm{fb}$ [accessed 9 June 2016]; Rebecca O'Connell, "Repaint the Smithsonian Collection With This Coloring Book," 2016, available online at http://mentalfloss.com/article/74671/repaint-smithsonian-collection-coloring-book [accessed 9 June 2016]; Michele Debczak, "The National Archives Has Released a Coloring Book of Retro Patents," 2016, available online at http://mentalfloss.com/article/75114/national-archives-hasreleased-coloring-book-retro-patents [accessed 9 June 2016].

17. Karla Kane, "Inside the Lines," Palo Alto Online, February 2016, available online at http:/ / paloaltoonline.com/news/2016/02/10/inside-the-lines [accessed 9 June 2016]; Jennie Slevin, "Reading Museum Launches Adult Colouring Book for \#colourourcollections Campaign," February 2016, available online at www.getreading.co.uk/whats-on/arts-culture-news/reading-museum-launches-adult-colouring-10826413 [accessed 9 June 2016]; Carl Hoover, "Staying in the Lines: Adults Find Creative Outlet in Coloring Books," Waco Tribune, March 2016, available online at www.wacotrib.com/entertainment/accesswaco/art/staying-in-the-lines-adults-find-creative-outlet-in-coloring/article_3d8da294-ae8f-5c76-bb01f60cdofa67aa.html?mode=jqm [accessed 9 June 2016]; "Friday Links: Women in Art, Cat Funerals, and Classical Star Wars," 2016, available online at https: / / artstor.wordpress.com/2016/01/29/ friday-linkswomen-in-art-cat-funerals-and-classical-star-wars / [accessed 9 June 2016]; Joyce Valenza, "It's \#colorourcollections or \#colourourcollections Week!," 2016, available online at http://blogs.slj.com/neverendingsearch/2016/02/01/its-colorourcollections-or-colourourcollections-week/ [accessed 9 June 2016]; Gary Price, "Roundup: Links to a Growing List of Library Coloring Books as 'Color Our Collections Week' Begins,” 2016, available online at www.infodocket.com/2016/01/29/roundup-links-to-a-growing-listlibrary-coloring-books-as-color-our-collections-week-begins-monday/ [accessed 9 June 2016].

18. For example: Harriet Mahood, "\#ColourOurCollections," Ego Sum, Ego Google, February 20, 2016, available online at http://nunastic.blogspot.com/2016/02/ colourourcollections.html [accessed 9 June 2016]; PF Anderson, "Color Our Collections via the University of Michigan Libraries," Emerging Technologies Librarian, February 2, 2016, available online at https: / / etechlib.wordpress.com/2016/02/02/ color-our-collections-via-the-university-of-michigan-libraries / [accessed 9 June 2016]; Rebecca Hopman, "\#ColorOurCollections Week 2016," A Mass of Odds and Ends, February 11, 2016, available online at https: / /rchopman.wordpress.com/2016/02/11/ colorourcollections-week-2016/ [accessed 9 June 2016].

19. "Where Should I Start with Adult Coloring?" Ask MetaFilter, available online at http://ask.metafilter.com/291387/Where-should-I-start-with-adult-coloring\#4222242 [accessed 5 May 2016]. 
While some of these outlets featured one or two coloring books only, most offered an introduction to the campaign followed by lists of selected coloring books. Not all of the outlets mentioned The New York Academy of Medicine as the originator of the campaign, but most did. However, many linked to our 2014 coloring book, created to hand out during a local event and included in early \#ColorOurCollections announcements, rather than the 2016 version made specifically for \#ColorOurCollections. Releasing and promoting a coloring book the Thursday or Friday before the week begins, which several libraries did, will likely gain it more attention by these online outlets.

A couple of pieces published after \#ColorOurCollections reflected on the campaign in thought-provoking ways. Digital Aladore, a personal blog tracking an e-book project, provided technical tips for libraries sharing images, from file naming and metadata standards to providing sufficient context for the images shared. ${ }^{20}$ A post from The Scholarly Kitchen, a blog on scholarly publishing, received even more attention. In her post, "What \#ColorOurCollections Suggests," author Jill O'Neill broke down the benefits of \#ColorOurCollections to participating institutions, saying that it boosted visibility and awareness "of otherwise hidden assets held in a collection"; "fostered re-use of the object or asset, without threat of damage or diminishing of its long-term value to the research community"; and encouraged engagement in a trackable way. ${ }^{21}$ This list delineates succinctly our goals for the project, and it was gratifying to read that our objectives translated to a wider audience.

\section{\#ColorOurCollections and Our Library}

\#ColorOurCollections had a measurable impact on our Library's social media reach, especially on Twitter, as measured by Twitter Analytics (analytics.twitter. com). We began promoting the campaign in January 2016; we gained 170 new Twitter followers that month, compared with 99 the month before. In February 2016, we gained 250 new Twitter followers, our best-ever month on the platform to date. From February 1 through February 5, our tweets gained 73,900 impressions (an average of 14,800 per day), compared to 41,200 impressions the following week. Our top tweet this year remains one announcing the campaign on January 29, 2016, which gained 19,842 impressions.

\footnotetext{
20. "Reflecting on ColorOurCollections," 2016, available online at https:/ / digitalaladore.wordpress. com/2016/03/17/reflecting-on-colorourcollections/ [accessed 9 June 2016].

21. Jill O’Neill, "What \#ColorOurCollections Suggests," 2016, available online at https://scholarlykitchen.sspnet.org/2016/02/09/what-colorourcollections-suggests/ [accessed 9 June 2016].
} 


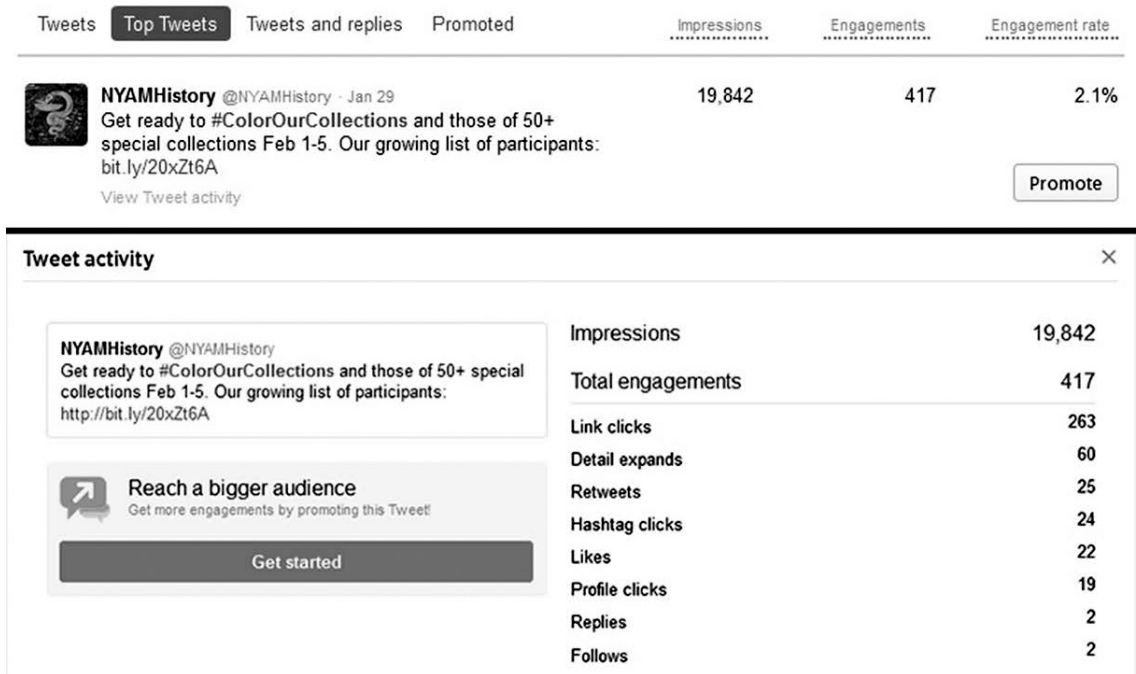

\section{Illustration 6}

We were able to identify our top tweet and track the campaign's impact using Twitter Analytics.

Our two best months to date on Instagram are January and February 2016, when we gained 100 and 176 followers, respectively. We manually track this growth; Instagram does not yet have a built-in analytics feature, though it does tell you how many times a hashtag has been used on the platform. As we only posted about the campaign once in January, it seems unlikely this was a factor in boosting our followers that month. But our increased presence on the platform during \#ColorOurCollections, along with following participating institutions' accounts and receiving follows in return, largely caused the February spike.

As stated earlier, we created a Pinterest account for use with the campaign. Organically, our account gained 141 followers during and after \#ColorOurCollections. The week served as an introduction to special collections' uses of Pinterest for our team; we may put our account to more use as our Library's digitization program expands.

The campaign had less of an impact on Facebook, as tracked by Facebook Insights; we gained 148 page likes in February but did not see a spike in page likes during the campaign. This was to be expected, as our campaign activity centered on Twitter and, to a lesser extent, Instagram.

Our blog, "Books, Health, and History," enjoyed a huge boost from \#ColorOurCollections, reflected in Wordpress's analytics. Our most popular blog entries on average receive 1,000 to 2,000 views per year. Our introductory \#ColorOur- 
Collections blog post, posted January 6, had more than 2,600 views in January and 3,600 views in February alone. "Books, Health, and History" typically gets 8,000-9,000 views per month; in January, it had nearly 12,000 views and in February it had 14,863 . As of this writing, five of the top ten most popular Wordpress posts published this year relate to \#ColorOurCollections. Our leading referrers to the blog (after Facebook and Twitter) also stem from that week: The Smithsonian Libraries, Library Journal Infodocket, the New York Public Library, Book Riot, and Ask MetaFilter top the list, all with campaign-related links.

We weren't the only participants to enjoy an online boost from \#ColorOurCollections. The Folger Library and the Bookbinders Museum reported their successes on Twitter.

Evidence that the internet loves to color: our wiki traffic jumped $7 \times$ normal rate thanks to \#ColorOurCollections folgerpedia.folger.edu/Color_Our_Coll...

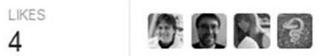
10:05 AM - 5 Feb 2016 47

Bookbinders Museum @BkBindersMuseum.Feb 5

20.9. @istolaryBrown No kidding. Our twitter traffic increased by several thousand. Yay for free marketing for a small newish museum!

\section{Illustration 7}

Other institutions reported the benefits of participation in \#ColorOurCollections in their own feeds.

For future campaigns, we will follow up with institutional participants to more formally gauge the impact of the campaign on their online reach.

\section{Lessons Learned}

Several factors contributed to the success of the campaign, and they can inform our future campaigns and those at other institutions:

\section{Timing}

We chose February 1-5, 2016, for our campaign both to give us sufficient time to prepare (we began planning in December) and because it did not coincide with other external events. Schools would be in session and not be in the midst of ex- 
ams, Bibliography Week in New York would be over, and major library conferences would not be taking place. In addition, the first week of a month is easy to remember and plan for, especially if a campaign becomes an annual occurrence. A week (or a five-day work week, in this case) is a sufficient amount of time to organically build interest in a campaign through online exposure. Picking a memorable time for a campaign that does not coincide with other events and choosing a sufficient duration for a campaign are important factors for the campaign's success.

We learned the hard way that campaign tracking also has to be well-timed. In planning a large campaign in the future, we would advise signing up for Hashtracking or a similar analytics service in the weeks before the campaign begins.

\section{Early Recruitment of Participants}

As discussed earlier, a month before the campaign we contacted about 130 organizations via e-mail, inviting them to participate. We also published a blog post on January 6 explaining the campaign and welcoming participants we may have overlooked in the e-mail. Getting early adopters was important, ensuring that the campaign would reach a broad audience, one much larger than had we created and shared a new coloring book on our own. Once highly regarded institutions with name recognition signed on, like the Smithsonian, the New York Public Library, and the Bodleian Library, we knew the campaign had promise. This outreach to institutions may also lead to other future collaborations. Planning ahead is key: if your library is looking for social media campaign participation, ask early and recruit widely.

\section{Ease of Participation}

While getting early buy-in from collaborating institutions was important, we also designed the campaign to be easy to join at any point during the week. All participating organizations had to do was share one image on the social media platform(s) of their choice using the hashtag. They were welcome to do more, and many did, but making the barrier to entry low allowed more organizations to take part. We also chose a type of campaign not limited by the focus of a library's collectionany collection item, be it an incunable, a photograph, or a patent, could be turned into a coloring page. Because of this, theology libraries could participate alongside college archives and historic homes. While creating a coloring page could take up staff time, libraries likely already had digitized excellent candidates for coloring images. In addition, free apps like Colorscape turn photographs into coloring sheets.

The campaign allowed organizations to work with resources and social media accounts they already had to promote their collections to the public in a new way. The University of Scranton Weinberg Memorial Library created several coloring books using images already in their digital collections and promoted 
them on multiple platforms (institutional blog, Twitter, Facebook, and Instagram). They point out that the original images were edited for the coloring books, and this created an opportunity to invite users to explore their digital collections in addition to engaging with them through coloring. Allowing participants to choose how they take part-including the social media outlets used, the collection items featured, and the time they dedicate to the campaign-makes campaigns more feasible for institutions deciding whether or not to join.

\section{Interactivity}

The fun of \#ColorOurCollections came from inviting members of the public to interact with collection items. The campaign inspired adults and children, academic and public library patrons, and everyone in between to pick up a crayon and take on the role of the colorist. A campaign that invites everyone to participate-either like this one, by coloring, or by contributing a story or video or photograph—has the potential to interest many more people than a campaign that, for example, passively asks for follows and retweets.

\section{Conclusion}

\#ColorOurCollections increased awareness of our institution's collections, and those of other participants, in measurable ways. The campaign offered a framework for engagement, facilitating connections to current and prospective patrons, as well as peer-to-peer relationships. Repeated name-checking of the Academy on social media and in the press raised awareness of our Library and its holdings and gained us new followers on our social media accounts. As a result of the campaign, we follow more of our peer institutions and know more about their collections. Our team is now aware, for example, that the National Archives' patent collections include fabulously intricate drawings and, more locally, that the Cooper Hewitt, just a ten-minute walk away, has astonishing $19^{\text {th }}$ - and early $20^{\text {th }}$-century Japanese cut paper illustrations. The \#ColorOurCollections campaign also proved a catalyst for discussions with other libraries about launching new campaigns. As of this writing, the Academy is in the planning stages of an October social media campaign launch in partnership with the Biodiversity Heritage Library, the Medical Historical Library at Yale University, and the Smithsonian Libraries. In addition to learning more about these institutions' collections, our engagement with these libraries' staff members contributes to the forging of relationships with our colleagues in libraryland.

\#ColorOurCollections demonstrates that the best collaborative social media projects are those that offer flexibility and freedom, in terms of both content and level of participation. Minimizing rules and restrictions allowed institutions of all sizes and capacities to join in and leverage the campaign to reach their own institutional goals. With the constraints of staff time and financial resources, we 
recognized the importance for institutions to have the freedom to participate at a level appropriate to their ability and needs.

A big part of the appeal for participants in \#ColorOurCollections was rooted in the campaign's broad call, and in the myriad ways institutions could invite their audiences to participate during a five-day window. While the campaign was based on social media, libraries could tailor their participation to in-person constituencies as well, with drop-in coloring sessions, printed handouts, and other coloring events. The campaign was expansive enough to accommodate not only varied library services, but it also facilitated institutional choice with regard to collection material shared. Libraries could choose images for \#ColorOurCollections from hidden collections, catalogued collections, items on exhibition, or other materials relevant to institutional calendars. Allowing institutions to choose their own materials for sharing and coloring facilitated individualized outreach and advancement of institutional missions, yet still within the auspices of the broader campaign.

The interactive element of \#ColorOurCollections also created an opportunity for existing followers and core supporters to read about collection materials, explore our catalog, and use the content creatively. \#ColorOurCollections allowed audiences to interact with rare material frequently housed in collections accessible to a limited audience, or material that may be known only to a well-connected researcher. It invited public users to adjust their understanding of what might be available in a library and to seek out new and unfamiliar sources for creative and scholarly work. Online audiences became ambassadors for our collections, sharing our sheets both online and as printouts, and reporting back that they and their chil-

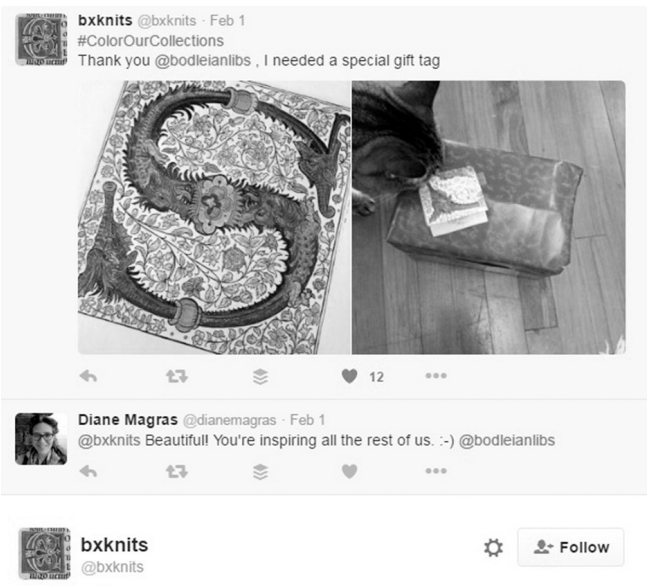

@dianemagras Aw thanks. I'm just having so much fun. Plus discovering new (to me) libraries, plus seeing the neat things people are doing dren or grandchildren loved the coloring sheets. Inciting our base facilitated an introduction of our Library to new followers drawn to our visual holdings and then interested and engaged followers more long-term by following us on social media.

\section{Illustration 8}

The campaign allowed followers, both those knowledgeable about special collections and those not, to use collection materials creatively and connect with previously unknown institutions. 
Finally, the exposure the campaign provided allowed people who had never heard of our Library previously to actively engage with our collection, remotely, and potentially in person. This experience was summed up succinctly by a woman who phoned the Library several weeks after the campaign. "Your coloring book said that I should contact you if I liked an image," she said. "I love the rhinoceros [a Dürer woodcut replicated in Gesner's 1551 Historia animalium, Liber I]. If I visit New York City, I want to see it in person.”

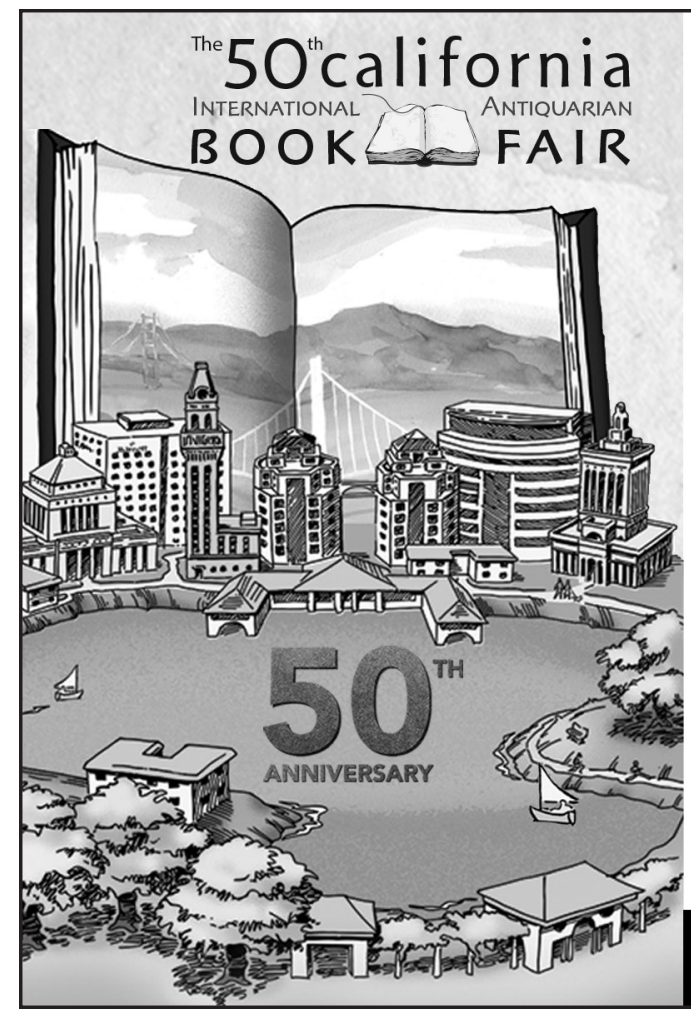

FEBRUARY 2017 FRIDAY $10^{\text {th }}$ SATURDAY $11^{\text {th }}$ SUNDAY $12^{\text {th }}$

\section{OAKLAND MARRIOTT CITY CENTER} 1001 BROADWAY • OAKLAND, CA 94607

Nearly 200 booksellers from around the world

\section{CABOOKFAIR.COM} 800.454 .6401

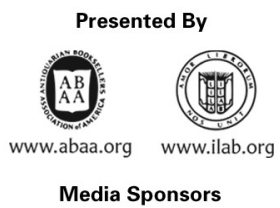

@) bartable
bart.gov/bartable
The Fair is BARTable!
(Uhyranicle ADMISSION - FSMS2 OFF 